The following is a pre-publication version of

Xenofontos, C. \& Andrews, P. (2014) Defining mathematical problems and problem solving:

Prospective primary teachers' beliefs in Cyprus and England, Mathematics Education Research fournal, 26(2), pp 279-299

DOI: $10.1007 / \mathrm{s} 13394-013-0098-\mathrm{z}$

Page numbers will not match those of the published version 


\title{
Defining mathematical problems and problem solving: Prospective primary teachers' beliefs in Cyprus and England
}

\begin{abstract}
A number of recent studies have investigated pre- and in-service teachers' beliefs concerning mathematical problem solving. However, researchers have typically examined participants' beliefs in relation to predetermined understandings of problem solving, assuming a definitional convergence among fellow scholars and teachers. Drawing on data from a small-scale comparative project, this paper discusses the similarities and differences of prospective elementary teachers' beliefs in Cyprus and England, about the nature of mathematical problems and problem solving. Twenty-four participants, each group of twelve from a well-regarded university in each country, were interviewed qualitatively at the exit point of their studies. Data analysis has revealed a variety of ways by which prospective teachers in both counties perceive the two notions. The results indicate that prospective teachers' beliefs are culturally located and that the concepts of “mathematical problem” and "problem solving” have different meanings across countries. Some implications for policy making are discussed at the end of the paper.
\end{abstract}

Keywords: mathematical problems, problem solving, prospective teachers'beliefs

\section{Introduction}

Following international trends for adapting education to the needs of the $21^{\text {st }}$ century (see Stein 2000; Tan 2003), the Cypriot and the English educational systems are currently undergoing curricular reform. In the new mathematics curricula of both countries, already available to the public in draft forms, problem solving is explicitly highlighted in the two documents as one of the main curricular goals. However, despite new and previous emphases on problem solving in the two countries, we still know little about how teachers construe problems and problem solving in relation to curricular intentions, not least because they tend to interpret and adapt intended curricula according to their experiences, capabilities and and beliefs (Stein and Kaufman 2010).

In this paper, we present and discuss the beliefs about the nature of mathematical problems and problem solving held by prospective elementary teachers at the point at which they exited their respective Cypriot and English undergraduate teacher education programmes. Conversations with academics at various international conferences - ICME11 (2008 in Mexico), CERME6 (2009 in France) and PME33 (2009 in Greece) - led us to conclude that notions of "problem" and "problem solving" are well-defined and beyond the need for further negotiation. Indeed, one colleague drew a parallel between these two notions and the concept of "point" in Euclidean geometry, arguing that everyone knows what a point is; hence, it is unnecessary to be defined. The evidence of our own research suggests something different. In an earlier study we found that prospective teachers, at the commencement of their undergraduate studies, hold substantially different beliefs about problems and problem solving from those of their peers across countries (Author 1 and Author 2 XXXX), highlighting how different school cultures had constructed different conceptions of problem and problem solving. In this paper we examine similar issues from the perspective of undergraduate teacher education students at the end of their respective programmes. In so doing we are attempt to see whether the outcomes of teacher education programmes, as agents of the system, are commensurate with either systemic expectations or perspectives typically held by the mathematics education research community. This paper is framed by the concepts mathematical problems and problem solving, discussed in the following pages. 


\section{On Mathematical Problems}

Throughout the mathematics education literature, the word problem is widely used, and yet evidence suggests that researchers have so frequently assumed a commonality of understanding that the word has acquired multiple and often contradictory meanings (Lester 1994; Schoenfeld 1992). For example, the word has polarised researchers between those who understand problems as routine exercises for the practice and consolidation of newly learned mathematical techniques, and those who view them as tasks whose difficulty or complexity makes them genuinely problematic or non-routine (Schoenfeld 1992; Goos, Galbraith, and Renshaw 2000). More recently, Haylock and Cockburn (2008) have defined problems as closed tasks, "involving the application of mathematics to a situation where there is a clearly defined goal” (p. 229). Our view is that definitions that acknowledge both forms of definition - routine and non-routine - cloud rather than clarify the issue by permitting discussion of two essentially distinct fields as though they were one. That is, they allow a situation to continue whereby, despite clear definitional variation, authors typically assume that a definitional convergence exists and carry on their research without providing any further explanations about their understanding of the concept.

With respect to the framing of our research, a mathematical problem presents an objective or goal with no immediate or obvious solution or solution process (Pólya 1981; Blum and Niss 1991; Nunokawa 2005). From this point of view, a key characteristic of a mathematical problem lies not within the problem itself, but with the person or people responsible for solving it. That is to say, the complexity of a problem is a function of the knowledge, experience and dispositions of the problem solver (Kilpatrick 1985; Schoenfeld 1985; Borasi 1986; Blum and Niss 1991). According to our reading of the literature, the relationship between the task and the solver, in so far as the former can be labelled a "problem", can be summarised as follows: Individuals must accept an engagement with the problem they intend to solve; they must have encountered an impediment and see no immediate solution process; and they must actively explore a variety of plausible approaches to the problem. With regard to the context of problems, we share Blum's and Niss' (1991) view, who distinguish between the problems embedded "in some mathematical universe" (p. 38) and those related to the real world. In other words, problems are either purely mathematical or applied. We consider this distinction of problems to be both logical and functional, since the same problem can exist in both domains, according to the context in which it is presented.

Applied mathematical problems have attracted much research attention. In school mathematics, they are typically construed as real-world tasks that describe a situation in a textual manner, usually presented under the label word or story problems (Jitendra, Griffin, Deatline-Buchman, and Sczesniak 2007). Their verbal form could involve "stating a symbolic form in words; instructions or goals for finding a solution; a mathematical context; or, a 'real world' or social/cultural context, real or imagined” (Chapman 2006, p. 211). Arithmetic word problems, typically encountered in elementary school mathematics, require the integration of several cognitive processes, such as understanding the language and factual information in the problem, devising and monitoring a solution plan, deducing (mostly quantitative) information from the given verbal data, representing the relationships between the elements that are described in the text of the problem, and executing appropriate procedural calculations (Nesher, Hershkovitz, and Novotna 2003). However, in his study with 161 elementary school pupils, Palm (2008) found that the participants were frequently using superficial strategies when solving word problems and that their solutions were inconsistent with the situation described in the tasks. Such findings are consistent with Greer's (1997) claim that many children employ naive processes for solving word problems, based on superficial features, 
such as key words in the text, which might lead to the choice of one of the four basic arithmetic operations.

The current upper-primary national mathematics textbooks of Cyprus - one of two research sites examined in this paper - use the term 'problem' to refer explicitly to textual tasks. Importantly, when solving such problems pupils are required to use certain schema/diagrams (Charalambous, Philippou, and Kyriakides 2004), which are based on Marshall's (1995) schema theory (ST). ST concerns arithmetic word problems and aims to provide solvers with a number of cognitive schemas that can be used as guides during the problem solution process. It exploits that simple external representations (diagrams) act as aids in retrieving and enhancing cognitive schema (Nesher and Hershkovitz 1994; Smidt and Weiser 1995). A schema is "a mental structure consisting of organized similar experiences, retrievable whenever an individual is faced with relevant problems" (Christou and Philippou 1998, p. 436). These schema (diagrams) help pupils to organise problem-related information in ways that facilitate problem translation and solution and, as far as elementary and middle school pupils with learning difficulties are concerned, the use of such diagrams can lead to significant improvements in scores on one-step addition and subtraction word problems (Jitendra 2002).

In general, with regards to the Cypriot mathematics classroom, mathematical problems are typically associated with word problems (Christou and Philippou 1998; Elia, Panaoura, Gagatsis, Gravvani, and Spyrou 2008). As far as the English mathematics classrooms are concerned, there is a tendency for teachers to appeal to real-life contexts for the purposes of motivating pupils, which at the same time seems to neglect the motivational power of mathematics itself (Rowland 2003). Similarly, Author 2 (XXXX) concludes that English secondary teachers see school mathematics as a set of tools applicable to the real world, while their Hungarian colleagues privilege the intrinsic properties of the subject, particularly problem solving, logical reasoning and proof.

\section{Mathematical Problem Solving - A Multidimensional Concept}

Recent international studies of pupils' mathematical problem-solving competence, such as the Programme of International Student Assessment - PISA (see for example OECD 2007) have indicated the importance of problem solving as a key element of pupils' learning. However, agreement as to the importance of problem solving says little about what the term may mean and "may mask very different views of what constitutes a problem and what kinds of problem solving abilities are desirable, teachable and evaluable" (Arcavi and Friedlander 2007, p. 356). In this respect, Chapman (1997) highlights the different ways in which the term problem solving is used. It can be a goal in itself, a process, a basic skill, a mode of inquiry, a form of mathematical thinking, and a teaching approach. That being said, our reading of the literature indicates that the prevailing perspectives seem to be problem solving as a process, problem solving as a curricular goal, and problem solving as an instructional approach.

From the first point of view (problem solving as a process), many writers have developed frameworks for analysing and describing the components of the process during which the individual is engaged with a mathematical problem. Pólya's (1945) well-known four-phase model has provided the basis on which other subsequent models have been developed. However, the majority of Pólya-style models have, according to Nunokawa (1994) and Kelly (2006), often been misinterpreted as a linear series of steps. Consequently, in attempts to avoid such misperceptions of linearity, Mason et al. (1992) and Nunokawa (1995, 2005) proposed models, which are explicitly circular, taking in consideration that the solver "needs to transform the situation or find new perspectives on it so that her/his mathematical 
knowledge can be applied to it” (Nunokawa 2005, p. 327). In such acts of transformation, both problem situation and solver knowledge may change, leading the solver to new mathematical ideas or methods. Embedded in most of these models are notions of heuristics (Pólya 1945, 1954; Hensberry and Jacobbe 2012). These are higher-order processes that guide the problem solution search and enable problem solvers to select from a reduced set of alternatives and order their solution process in a sequence of steps. The better known heuristics, introduced by Polya (1945) are trial-and-error, analogy, generalisation, working backward, and draw-a-figure.

The second perspective refers to explicit references to problem solving in the intended curriculum of a country. For example, it is one of the five fundamental mathematical processes identified by the National Council of Teachers of Mathematics (NCTM 2000) and, consequentially, a key objective of many US states' curricula. The Singaporean curriculum places problem solving at the heart of the school mathematics experience (Fan and Zhu 2007). However, the emphases a system places on problem solving varies greatly. For instance, the Chinese curriculum presents problem solving as a key learning outcome, while the US, as reflected in the NCTM's standards, emphasises problem solving as both outcome and instructional approach (Cai and Nie 2007).

The third perspective concerns the ways teachers exploit mathematical problems in their teaching. For instance, teachers may emphasise the application of pupils' mathematical knowledge for the solution of routine and non-routine problems (teaching for problem solving), may use problems to facilitate pupils' learning of mathematical content and how that new content is related to the mathematical knowledge they already have (teaching via problem solving), or use problems to facilitate pupils' acquisition of techniques concerning how to treat problematic situations, manage their solving processes, and put forward their thinking (teaching about problem solving) (Schroeder and Lester 1989; Nunokawa 2005).

\section{Teachers' beliefs on mathematical problem solving}

In the field of mathematics teacher education there is a widely shared assumption that what teachers believe is a significant determinant of what gets taught, how it gets taught and what gets learnt in the classroom (Ernest 1989, Thompson 1984; Chapman 2003). Consequently, not only would examination and analysis of beliefs facilitate better focused teacher education programmes (Cooney, Shealy, and Arvold 1998), but also "being able to identify and describe the mechanisms underlying the influence of beliefs on instructional interactions would deepen and enrich our understanding of the teaching process" (Aguirre and Speer 1999, p. 327). Many studies have highlighted the importance of examining, analysing and changing teachers' beliefs to facilitate the implementation of mathematics curricular reforms (Ernest 1989; Handal 2003; Savizi and Shahvarani 2007), not least because without shifting teachers' beliefs, changes can 'be cosmetic, that is, a teacher can be using new resources, or modify teaching practices, without accepting internally the beliefs and principles underlying the reform" (Handal and Herrington 2003, p. 62). Such issues are well highlighted by, for example, Cohen's (1990) case study of Mrs Oublier and the dissonance of her beliefs and practice. Also, it is important to acknowledge that teachers' beliefs about mathematics (see Correa, Perry, Sims, Miller, and Fang 2008; Santagata 2004; Author 2 and Collaborator XXXX) and its teaching (see Leung 1995; Author 2 XXXX; Givvin, Hiebert, Jacobs, Hollingsworth, and Gallimore 2005) are more closely aligned within individual countries than across them. More recently, in an attempt to explain how culture informs teachers' beliefs and practices, Author 2 (XXXX) has proposed that teachers work within three curricula; an intended, an idealised and a received curriculum. That is to say, they are constrained (or liberated) by the systemic curricular model within which they operate; they approach their 
work with a unique set of articulable personal goals, and they work within cultural norms where articulation is restrained.

Our reading of the literature has confirmed that few studies have examined teachers' mathematical problem-solving-related beliefs. Of course, while authors like Cooney (1985) and Thompson (1985) have considered problem solving in their work on mathematics teachers' general beliefs, the focus of their studies "was more on the teaching of mathematics as opposed to teaching problem solving as an explicit topic" (Chapman 1997, p. 204). From the small number of studies that have examined teachers' problem solving-related beliefs two themes have emerged. The first theme concerns in-service teachers' beliefs about problem solving in mathematics classrooms. Typically within the framework of "traditional versus constructivist beliefs", problem solving is associated with the latter (see, for example, Handal and Herrington 2003; Shahvarani and Savizi 2007; Chapman 1997, 2006). Studies in this category have adopted a similar understanding of what problem solving means. In this respect, Anderson's and her colleague's work not only represents one of a few attempts to examine explicitly teachers' beliefs about problem solving (see Anderson and White 2004; Anderson 2005; Anderson, White, and Sullivan 2005) but also presents a well-defined and predetermined understanding of problem solving. For them it is

"the process of students engaging in rich mathematical investigations, exploring and reasoning about new mathematical ideas individually or in small groups, investigating unfamiliar problems, developing a range of solutions to openended tasks and posing problems for other students to solve" (Anderson and White 2004, p. 127)

The second theme examines the impact of certain training programs on pre- and inservice teachers' problem-solving beliefs. Again, as with studies in the first category, problem solving is associated with constructivist, inquiry-oriented learning. Research in this category can also be clustered in two sub-categories. In the first, participants are treated as teachers, and the main focus is enhancing their pedagogical knowledge and skills for problem solving in classrooms. Such examples are the studies of Lam (2006), and Leikin and Kawass (2005). In the second, participants are seen as both learners and teachers. The focus is developing participants' skills as problem solvers and pedagogical knowledge about problem-solving instruction (see Chapman 1999; Leikin 2003; Metallidou 2009; Taplin and Chan 2001; Van Dooren, Verschaffel and Onghena 2003).

Clearly, research on teachers' problem-solving-related beliefs is limited. In all papers we reviewed, researchers had their own understanding on problem solving, and examined their participants' beliefs in relation to that understanding. However, in our opinion, this is not always productive, as the results from international-comparative studies on problem solving reveal enormous disparities on how the notion of problem solving is conceptualised in different educational settings (Author 1 XXXX). For example, Zambo and Hong (1996) examined South Korean and US elementary teachers' beliefs and practices pertaining to problem-solving instruction and identified a number of differences. The Korean teachers, for instance, rated themselves and their pupils higher in problem-solving ability than their colleagues in the US; they perceived their mathematics textbook as a more valuable source for problem-solving instruction and word problems; and, they agreed, more strongly, that pupils should know the key-word approach for solving problems. The US teachers, on the other hand, reported a more frequent use of calculators, manipulatives, and small group instruction. Arcavi and Friendlander (2007) interviewed the managers of different curriculum development projects in Israel and concluded significant differences among the various theoretical and practical approaches to problem solving, even within the same community (curriculum developers), focusing on the same target population (elementary schools) within a centralised system (in Israel) with a uniform syllabus. From the Australian perspective, 
Clarke, Goos, and Morony (2007) discuss the evolution of the problem-solving research and describe the shift of the research interest from theory development (early 90s) to the investigation of classroom practices. The fact that there is no homogeneity, in so far as perceptions of and research on problem solving within single countries are concerned, has provoked our interest, from a comparative perspective, in the field.

\section{The project - Participants and data collection}

This paper is based on data from a small-scale comparative study of prospective elementary teachers' beliefs about problem solving, in Cyprus and England. The main purpose of the project was to examine comparatively cultural similarities and differences in prospective teachers' beliefs about problem solving at two levels: the Entry and the Exit level. These two groups reflect, essentially, an opportunity sample linked to our respective locations and the site of the first author's PhD study. However, a particular point of interest lay in the fact that Cyprus, as a former colony of the UK, retains, within its educational traditions, a colonial legacy. Thus, we were particularly interested in understanding how current perspectives on problem solving in the two countries could be traced to a single root.

Among others, two volunteer groups of final-year (Exit) university teacher education students, from Cyprus and England, participated in semi-structured interviews conducted by the bilingual first author, in Greek and English respectively. Students at both universities volunteered to participate subsequent to an open invitation. Thus, both samples were simultaneously self-selected and convenience. All participants had a major in primary education and were close to the completion of their final-year assessments. Both universities, according to various national measures, are well regarded for their teacher education programmes. Our objective, with respect to this paper, was to elicit prospective teachers' problem-solving related beliefs at the point of exit from their respective courses. Each cohort comprised twelve prospective teachers: the Cypriot group included eight females and four males, while the English included only females. The interview questions drew on Ernest's (1989) model of teachers' beliefs, which comprises three dimensions: beliefs about the nature of mathematics, mathematics teaching, and mathematics learning. In our study, two additional dimensions related to prospective teachers' mathematics and mathematics teaching self-efficacy were introduced. The semi-structured interviews, which were audio-recorded and later transcribed, did not exceed 40 minutes and took place at the participants' universities. The interviews were based on the same general questions for both countries. The interview protocol is presented in the Appendix.

\section{Data analyses}

Data analysis took place in two stages. At the first stage, the employment of a datadriven coding approach (Boyatzis 1998; Kvale and Brinkmann 2009), exploiting the constant comparison process outlined by Strauss and Corbin (1998), led to the identification of a seven-theme framework. These broad and culturally neutral themes were common to both groups, which were (1) the nature of mathematical problems; (2) the nature of mathematical problem-solving (MPS); (3) affective issues of learning; (4) cognitive/metacognitive issues of learning; (5) the self as solver; (6) explicit pedagogic practice, and (7) the self as teacher.

At the second stage, a form of phenomenography was employed. Conventionally a phenomenographic researcher, by attempting to see the world through the eyes of people experiencing it, makes statements about other people's experiences of the world (Marton 1981). Such research, in relation to a range of phenomena, has shown that there are limited ways in which any given phenomenon is experienced (Cope 2004). While our research shares certain similarities with the traditions of phenomenography, we would argue, for two reasons, that it is not strictly phenomenographical. First, in phenomenographic research, interviews 
are typically open (Marton 1994), while, in our case, they were semi-structured. Secondly, examining the variation in our participants' beliefs occurred late in our data analysis, while in phenomenographic research this occurs at very beginning (Sin 2010). Thus, our view is that we appropriated the the phenomenographic aim of uncovering the finite set of categories of conceptions of a phenomenon (Herbert and Pierce 2011).

Again, following Strauss' and Corbin's (1998) constant comparison process, we returned to our data. At this stage, analysis was underpinned by the seven-themed framework, as we tried to identify the various ways our participants talked about each theme. At first, we ended up with more than 50 codes for each group. Then, we tried to find links between the various codes of each group individually, and developed sub-themes related to one of the seven general themes. Below, an example from the Exit English group analysis is presented, illustrating the relationships between codes, sub-themes, and themes.

- Examples related to real life

- Problems are real world situations

- Problems provide context for applying maths

- Problems should have an observable real life purpose

- Problems-a way to connect maths and real life

- Problems-practical skills for real life

- Problem - needs investigation - not a simple task

- No obvious answer or method for a problem

- Someone may know method; someone else may not
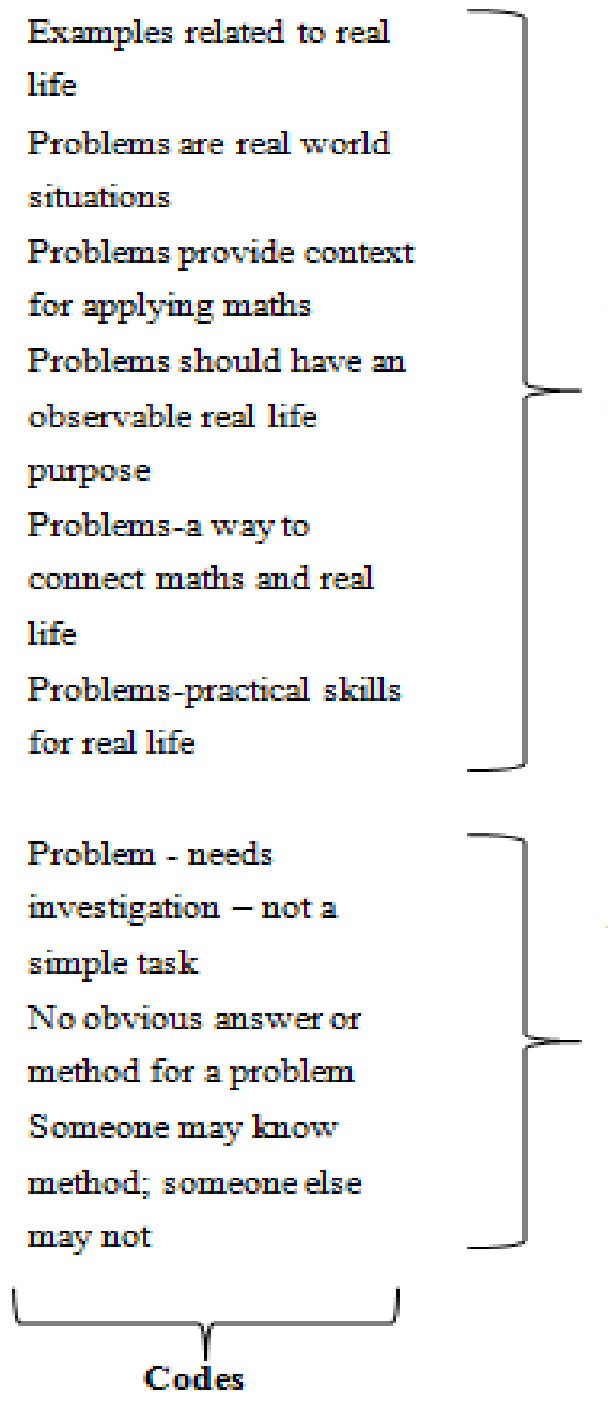
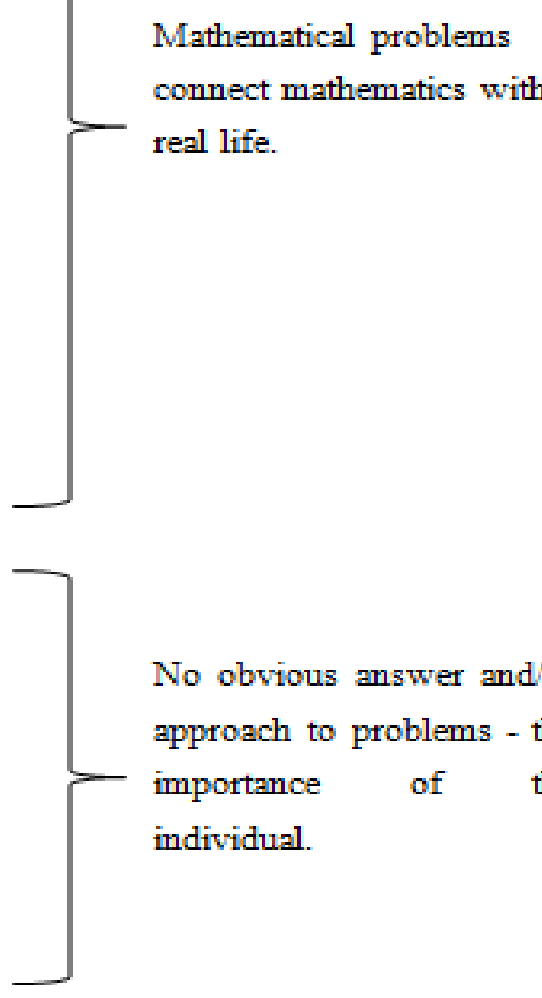

No obvious answer and/or approach to problems - the importance of the individual.

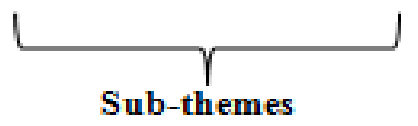

The nature of mathematical problems

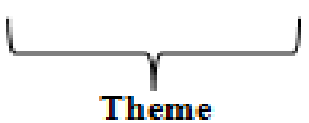

Fig. 1: Examples of codes, sub-themes, and themes from the English Exit data.

In this paper, the first two themes are presented and discussed, and include no judgments about the individual and her/his competence as either solver of problems or prospective teacher. 


\section{Cypriot Perspectives on the Nature of Mathematical Problems}

With respect to the Cypriot prospective teachers' beliefs about mathematical problems, three sub-themes were identified:

a) Mathematical problems as stories related to real life.

b) Problems related to schema theory - The four arithmetic operations.

c) Heuristics-related problems.

Below, these themes are presented and supported by representative quotes.

\section{Mathematical Problems as Stories Related to Real Life}

For all twelve prospective teachers, mathematical problems were seen as real-life situations embedded within a text ${ }^{1}$. According to Nefeli,

to have a mathematical problem, in my opinion, there should be a problematic situation, ok? There is some given information in the problem, and you will be asked to find something, the desired outcome. (...) For example, 'a potatoproducer sells potatoes for 50 cent per kilo. If he sold $70 \mathrm{~kg}$ yesterday, how much money did he make?' (...) It is a verbal description, with given information, and in the end you are asked to find something.

With regard to the textual-verbal context, Alexandros added that in problems there are some roles and personae related to the situation. He said that "in problems there are 'people' involved; maybe, it is a more complex situation. This is different from simple equations, let's say. The plot in problems makes numbers real". In a similar vein, Eleftheria explained that what differentiated problems from simple sums was that:

we can see other factors in the problem, like roles. It is not a simple sum, five plus three equals eight. It is a problematic situation. You begin with "someone had something", "something happened in the end", you are asked to find something and you need to process the information in order to solve it.

Other participants offered examples of activities they had engaged with during their school placement. For example, Antonis described an activity performed with his pupils. His response highlights the notion of the textual/real-world nature of problems.

The lesson was about priority rules in arithmetics. I gave pupils two problems with the same numbers in written form. I don't remember the exact numbers: let's say five, six, and seven. In one problem, the answer was $(5+6) * 7$, while in the other it was $5+(6 * 7)$. It was about a flower shop and flowers. I don't remember the problems. Anyway, in both problems it was implied where the brackets should be. Pupils had to solve two different sums with the same numbers, and they faced a cognitive conflict. "I have the same numbers, but the brackets are in different positions”.

Briefly, all twelve prospective teachers construed mathematical problems as real-world verbal tasks. In such a verbal context, a reference to human characters and/or real-world objects should be made.

1 The participants referred to the existence of a written text, as opposed to (a) an oral text or presentation of the task and (b) a mathematical task either without a text or not a real-life related one. 


\section{Problems Related to Schema Theory - The Four Arithmetic Operations}

Nine out of the twelve prospective teachers also talked about mathematical problems in relation to the four arithmetic operations (addition, subtraction, multiplication, division). For them, problems of this kind could be clustered according to the cognitive schema required for solving them. The participants referred to four schemata: change, grouping, comparing, and analogy. Alexandros, for instance, gave some examples related to the schemata:

Well, an analogy problem would be, "Someone bought 15 pencils for 3 cents each. How much did he pay?" This is an analogy problem. Another one would be "Yiannis had some money in the beginning and his parents gave him $€ 5$ more. Now he has $€ 15$. How much did he have in the first place?" This one is different because it is a change problem. There are also problems like, "Petros has this amount and Giorgos has this amount. How much more does Petros have?" This is a problem of comparison.

Marianna talked about her teaching experience during her placement, and referred to "schema-based" problem solving activities she had done with her pupils.

Basically, we were learning about the schemata. In that lesson, I was giving them problems and they had to work in groups and find the given information. I didn't tell them which schema was related to each problem. I didn't say "this problem suits this schema”, no. They had learned about some schemata already. I would give them problems and they tried to find out how to solve them. I visited each group to see how pupils were thinking and what they were doing. The answer wasn't that important. Pupils being able to explain their thoughts counted more.

To sum up, the prospective teachers talked here about the real-world verbal tasks labelled as problems that appear in the upper-primary National Textbooks of Cyprus (Charalambous et al. 2004) and are based on Marshall's (1995) Schema Theory. In particular, four types of tasks are included in the textbooks: problems of change (something happens to a given quantity addition or subtraction), problems of comparison (comparing quantities with addition, subtraction, multiplication or division), problems of grouping (putting quantities together addition or subtraction), and problems of analogy (if... then... multiplication or division).

\section{Heuristics-Related Problems}

According to six prospective teachers - that is half of the group - had another perspective on mathematical problems related to Pólya's heuristics. None of the participants, however, made any reference to Pólya's name. Problems of this kind, they argued, are distinguished from those based on cognitive schemata, as described above. Antonis' typical quote shows how he and his five classmates distinguished between the two categories:

As we have learnt in Didactics of Mathematics ${ }^{2}$ there are two kinds, two big categories. On the one hand, we have 'routine problems' and on the other, we have 'problems of strategies's, if I'm not mistaken. The routine problems are based on the four algorithms, addition, subtraction, multiplication, division. For the problems of strategies you need to think out of the box; algorithms are not enough for solving them. Other procedures are required.

2 The student here refers to a module of their undergraduate program.

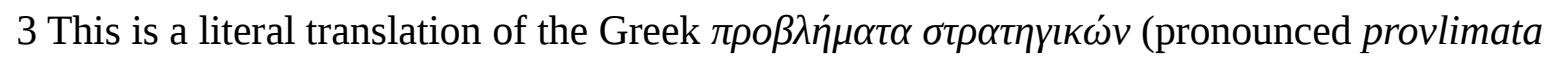
stratigikon). An accurate translation of this would be "problems that require strategies in order to be solved". 
In her typical response, Despina referred to try and check ${ }^{4}$, do a table, make a sketch. I don't remember all the strategies, but there are other strategies as well". Some of the prospective teachers gave examples of activities based on heuristics-related problems they did in their classrooms during school experience. Eleni, for instance, shared a personal experience, for which her teaching objective was to introduce pupils to the strategy of organising data in tables:

Basically, at the time we were learning about strategies. This lesson was about "doing a table". I gave them a problem about some animals' characteristics. I wrote the problem on the black board. Pupils shared their ideas. We all agreed that the best thing to do was a table. Then, according to the given characteristics, we started excluding some animals. In the end, the pupils themselves found out which animal was in which cage.

In summary, the six prospective teachers here referred to another type of task labelled as problems in the upper-primary National Textbooks of Cyprus. Like the tasks of the previous category, the so-called Strategy Problems are presented in realworld contexts, in which human characters are involved. It should be noted that tasks of this kind appear significantly less than those based on Schema Theory.

\section{The Cypriot Perspectives on the Nature of Mathematical Problem Solving (MPS)}

\section{MPS as the Process of Understanding and Working out a Problem}

All twelve prospective teachers used the term "process" to describe MPS. For the whole cohort, understanding the problem, extracting the given information in order to uncover the desired outcome, are basic components of MPS. In addition, a cyclic perception of the process was implied by most interviewees. In general, participants' responses with respect to the nature of MPS were homogenous. As Eleni said,

Mathematical problem solving is a process with some strategies you know and might help you reach an answer. (...) First of all, one has to understand what the problem states, and after that, move on to the algorithms. Of course, he/she has to think whether addition or subtraction is necessary, let's say, or if it is a combination of both, or something else. After reaching a resolution, he/she needs to understand the result, whether it is logical, according to the data given. Maybe, he/she will need to go back to understanding the problem and the algorithms applied, and then return back to the result.

Alexandros expressed similar views. In addition, he indicated that his beliefs about the nature of MPS had changed after a university module:

Before Didactics of Mathematics, mathematical problem solving meant the answer to me, the act of solving the problem. After class, however, and this opinion is ingrained in me now, mathematical problem solving became a matter of finding; it's the process you use until you reach a resolution, regardless if the answer is right or wrong.

With respect to the whole process of tackling a problem, five of the participants explicitly used words and expressions that confirmed their beliefs about the verbal-textual nature or

4 This is the Greek term for trial and error. 
problems, such as, “...read the problem word-by-word” (Nefeli), “...in order to avoid getting lost in the text..." (Eleftheria), "the first thing is about reading the problem...” (Despina).

In short, the Cypriot prospective teachers here explicitly used 'process' to define MPS. For them, MPS is seen as the open process during which a solver interacts with a problem. In such a process, understanding and interpreting the language of the task is essential.

\section{English Perspectives on the Nature of Mathematical Problems}

As far as the English prospective teachers' beliefs about mathematical problems go, two sub-themes were identified:

a) Mathematical problems connect mathematics with real life.

b) There is no obvious answer and/or approach to problems - the importance of the individual is emphasized.

These themes are presented below and supported by representative quotes.

\section{Mathematical Problems Connect Mathematics with Real Life}

For all twelve participants, mathematical problems were seen as tasks or activities that connect mathematics with real life. According to Lesley's definition, a problem

...is another version of maths (...) [Pupils] can see how maths can be used every day 'cause problems are more about using maths in an everyday situation rather than solving sums, written out sums. So they can see how maths is actually there

to help them when they go out into the world.

All informants provided examples of tasks they considered to be mathematical problems or problem-based activities they had used during their school placement. Stacey, for instance, talked about organising a party: "You need to arrange an end-of-term party, and you've got this much budget. You've got, I don't know, tickets to book. And refreshments and things like that. How are you going to ensure that you have a big enough budget to cover things?” An interesting example was that of Stefanie, who baked cookies with her pupils to help them understand the concept of ratio:

I did cooking with them this week. They had to cook so they can think about what the ingredients weigh. The evidence is in eating, isn't it? If they add too much flour or too many eggs, it is not going to work. So, they can see why it's important to be accurate about different things.

To sum up, all the English prospective teachers saw mathematical problems as a kind of task or activity that links the world of mathematics to the real world. In their eyes, such tasks increase pupils' understanding with respect to the practical applications of mathematics.

\section{No Obvious Answer and/or Approach to Problems - The Importance of the Individual}

Eight of the prospective teachers believe there should not be any direct approach to the resolution of a problem. In addition, all of them argued that solvers should not be able to see the answer(s) immediately. In Joanne's words, a problem "is something that needs solving, something that you don't know how to, initially, em, but you don't know the actual answer in 
the end". Overall, a consensus emerged from the eight informants' responses, which Caroline summarised well:

A problem, I think, is when you have to apply several different methods or areas of mathematics to work out the answer, whereas in a mathematical question, like 54 and 2 or something, there's one answer so it is very easy to work out. There is not much thinking to go into it. In a problem, pupils have to get numbers from it and realise what method to use. Are they going to use plus, minus, times, or divide? What are they going to equate with what?

The eight prospective teachers highlighted the importance of the individual solver in defining a mathematical problem. For them, a task could be a problem if, and only if, there was a blockage between the individual solver and the solution of the task at hand. Gabrielle's response was not atypical. She gave an example of a sum, 10 plus 15, and argued that it could be a problem,

if [the pupils] are going to break it up and think about how it is added together. For older children, it will just be, like, 25. 'Cause they can just do it; they've learnt that. See, that's what I mean. If they've learnt it, and they can just run that off, that's not really problem solving. That's just a fact they've learnt. And then, em, on the other hand, you've got the little ones who can't; they are not there, yet.

Briefly, the prospective teachers here highlighted the role of the individual in defining mathematical problems, as highlighted above in the literature. For them, a task is only a problem to someone when there's a blockage between the solver and the solution, which cannot be overcome with the application of a direct method or approach.

\section{The English Perspectives on the Nature of Mathematical Problem Solving (MPS)}

\section{MPS as the Process of Understanding and Working out a Problem}

For all twelve prospective teachers, MPS was seen as an open process during which solvers have to understand the situation at hand, adapt previous knowledge and skills, and attempt a resolution. They all claimed that understanding the situation was the key element in the process. Nicole, for example, pointed out the significance of

understanding the question, and the strategies that you've got to use. But then, you could be going in the right way but have the wrong answer. Because you've got to understand the question, you've got to know the strategies to use, work out the question, do the work right and then find the answer.

All prospective teachers highlighted the necessity of basic mathematical knowledge and skills before any attempts for resolution. Lesley's quote was typical. What is significant for the MPS process, apart from understanding, is "also the knowledge of the different, em, like addition, subtraction, multiplication, division, and being able to work out which way, which sum you need to work on to get to the answer you want. So, like a broad idea of maths, also being able to implement it by themselves". In general, there was a consensus between these prospective teachers' responses with regard to MPS. Stacey's quotation summarises her classmates' opinions. As stated, this was the most important issue in MPS,

being able to understand what's asked. So, being able to understand and interpret the question. Or the problem. Em, identifying which skills you need to use to find 
the solution. And then, probably being able to apply those skills successfully in order to solve a problem. So, like, logic, skills, and things like that.

In summary, while the majority of the prospective teachers here did not explicitly use the word 'process' to define MPS, their responses alluded to an open process during which the individual interacts with the task in order to find a resolution. In such a process, understanding the situation and what is needed to be done appears to be a major issue.

\section{Discussion}

The two cohorts expressed both similar and different beliefs about the nature of mathematical problems and problem solving. Both groups saw mathematical problems as real-world tasks. This belief seems to be a restricted perception of what the general mathematics education literature says, namely, problems can either be related to real-world or be purely mathematical, depending on the context within which they are presented (Borasi 1986; Blum and Niss 1991). Such a finding confirms the conclusions of earlier Cypriot (i.e. Christou and Philippou 1998; Elia et al. 2008) and English (i.e. Rowland 2003) singlenational studies.

Despite this apparent similarity, further analysis of the two groups' beliefs revealed substantial differences. For the Cypriot prospective teachers, problems were equated with word problems (Nesher et al. 2003; Jitendra 2002). That is, Cypriot prospective teachers highlighted the necessary existence of a verbal context in written form as a general feature of problems. Furthermore, the Cypriot responses formulated a dualistic belief about the types of problems. On the one hand, there were the so-called routine problems, associated with Marshall's (1995) Schema Theory and the use of the four arithmetic operations. Tasks of this kind are common in Cypriot classrooms, especially at the upper-primary level (Charalambous et al. 2004). On the other hand, the prospective teachers pointed out a separate category of problems, those related to Pólya's heuristic strategies. This dualistic belief is not surprising, especially when both types of tasks described by the participants appear in the National Textbooks of Cyprus, and are explicitly characterised as problems. However, the textbooks are dominated by the former type, while examples of the latter are extremely rare. It is worth mentioning that a similar dualistic belief emerged from Callejo's and Vila's (2009) case study of two 12-year-old Spanish pupils of high academic performance, who talked about "usual problems" (problems solved without difficulty if one knows the techniques and mechanisms, and has a clear idea of the concepts) and "thinking problems" (search processes must be developed where difficulties are encountered and common sense must be used and heuristic strategies applied).

Interestingly, the majority of the English participants regarded the role of the individual solver in labelling a task, as a problem in itself. According to them, a problem is only a problem to an individual who cannot apply any direct method for resolving it, an opinion held by a number of experts in the field of mathematical problem solving (e.g. Schoenfeld 1985; Kilpatrick 1985; Borasi 1986; Blum and Niss 1991).

The Cypriot and the English prospective teachers expressed similar beliefs about the nature of mathematical problem solving. For both groups, problem solving implied an open process during which one engages with a problem. Such beliefs are not unrelated to the ideas of Mason et al. (1982) and Nunokawa (2005), whose problem solving models, in an attempt to avoid the perceived linearity of other Pólya-style models, are explicitly circular. In addition, both groups emphasised the importance of being able to interpret and understand the problem task in order to identify what needs to be done. By way of difference, most English prospective teachers highlighted the importance of knowing basic mathematics before being able to solve problems. For these prospective teachers, basic mathematics comprises the four 
operations of arithmetic, and knowledge of basic mathematics is synonymous with speedy calculation. In other words, for the English group, problem solving succeeds the mastering of basic mathematical knowledge and facts. Such a perspective finds resonance with research on English mathematics teaching, showing how topics are always introduced at an elementary level, taught over a small number of lessons, before being picked up again later, but rarely in ways commensurate with developmental objectives (Jennings and Dune 1996; Kaiser 2002, Kaiser, Hino, and Knipping 2006). Interestingly, all Cypriot prospective teachers used the word process explicitly, whereas only one English student did. All other English participants talked about the features of problem solving, namely understanding, knowing basic mathematics, adapting and applying. Interestingly, for more than twenty years the English National Curriculum has incorporated an assessed objective related to school students being able to use and apply mathematics. The vocabulary used by these prospective teachers was entirely in accordance with this objective, and has, we argue, become an element of the received curriculum of English education. With respect to the Cypriot prospective teachers' use of process, it is quite possible that they had a specific definition in mind concerning problem solving as a process (Chapman 1997) and wanted to demonstrate their acquisition of an appropriate "technical vocabulary” (Beyerbach 1988).

\section{Conclusion}

Our findings show that, at the exit point of their undergraduate programmes, prospective teachers' beliefs about the nature of mathematical problems and problem solving are culturally located. Furthermore, their beliefs seem to be related to the general cultural aspirations and perceptions regarding problems and problem solving, as our participants' responses find resonance with the findings and conclusions of other studies in the two countries. Within both cohorts, a big convergence of beliefs was observed. It is quite possible that certain values of the educational systems of Cyprus and England were explicated through our participants' voices, and could be perceived as indicators of the powerful role of the received curriculum (Author $2 \mathrm{XXXX}$ ). Of course, in this paper we do not examine the impact of the undergraduate programmes on prospective teachers' beliefs. Nevertheless, given that out participants were soon to receive their teaching qualifications, we were interested in offering a snapshot of the problem solving beliefs of those entering the teaching profession in both countries.

Many international comparisons seem to have fallen into the trap of assuming that things with the same name must have the same function in every culture (Grant 2000; Clarkson 2009). As indicated at the beginning of this paper, both the Cypriot and the English systems are currently undergoing curricular reform. As far as we have discerned, both documents make references to problem-solving, and to pupils being able to solve mathematical problems. Yet, as with the previous primary mathematics curricula of Cyprus and England (Author 1 and Author 2 XXXX), little information seems to be provided with respect to what constitutes a mathematical problem, and how problem-solving is systemically perceived. Promoting problem solving simply because other, more 'mathematically successful' nations do (see for instance the national curriculum of Singapore, Fan and Zhu 2007) seems naïve and educationally inadequate. If problem-solving is to be a core objective of mathematics teaching and learning (as the new curricula imply), we would like to recommend to curriculum writers, in both countries, that they publish an appropriately researched document explicating the systemic construal of mathematical problem and problem-solving, as well as the expected learning outcomes in relation to problem-solving. Also, it is essential that test writers and researchers working in the field clarify what they 
mean by these terms when using them. We consider our work as a small, yet important, step that urges the necessity of these concepts to be clearly defined in every instance.

\section{References}

Aguirre, J., \& Speer, N. M. (1999). Examining the relationship between beliefs and goals in teacher practice. The journal of mathematical behavior, 18(3), 327-356.

Anderson, J. (2005). Implementing problem solving in mathematics classrooms: What support do teachers want? In A. Downton, D. Gronn, M. Horne, A. McDonough, R. Pierce, \& A. Roche (Eds.), Building connections: Theory, research and practice. Proceedings of the 28th Annual Conference of the Mathematics Education Research Group of Australasia (pp. 89-96). Melbourne: Victoria.

Anderson, J., \& White, P. (2004). Problem solving in learning and teaching mathematics. In B. Perry, G. Anthony, \& C. Diezmann (Eds.), Research in mathematics education in Australasia 2000-2003 (pp. 127-150). Flaxton: Post Pressed.

Anderson, J., White, P., \& Sullivan, P. (2005). Using a Schematic Model to Represent Influences on, and Relationships Between, Teachers' Problem-Solving Beliefs and Practices. Mathematics Education Research Journal, 17(2), 9-38.

Arcavi, A., \& Friedlander, A. (2007). Curriculum developers and problem solving: the case of Israeli elementary school projects. ZDM, 39(5), 355-364.

Beyerbach, B. A. (1988). Developing a technical vocabulary on teacher planning: Preservice teachers' concept maps. Teaching and Teacher Education, 4(4), 339-347.

Blum, W., \& Niss, M. (1991). Applied mathematical problem solving, modelling, applications, and links to other subjects-State, trends and issues in mathematics instruction. Educational Studies in Mathematics, 22(1), 37-68.

Borasi, R. (1986). On the nature of problems. Educational Studies in Mathematics, 17(2), 125-141.

Boyatzis, R. E. (1998). Transforming qualitative information: Thematic analysis and code development. London: SAGE Publications.

Cai, J., \& Nie, B. (2007). Problem solving in Chinese mathematics education: research and practice. ZDM, 39(5), 459-473.

Callejo, M. L., \& Vila, A. (2009). Approach to mathematical problem solving and students' belief systems: two case studies. Educational Studies in Mathematics, 72(1), 111-126.

Chapman, O. (1997). Metaphors in the teaching of mathematical problem solving. Educational Studies in Mathematics, 32(3), 201-228.

Chapman, O. (1999). Inservice teacher development in mathematical problem solving. Journal of Mathematics Teacher Education, 2(2), 121-142.

Chapman, O. (2003). Belief structure and in-service high school mathematics teacher growth. In G. Leder, E. Pehkonen, \& G. Törner (Eds.), Beliefs: a hidden variable in mathematics education? (pp. 177-193). Springer.

Chapman, O. (2006). Classroom practices for context of mathematics word problems. Educational Studies in Mathematics, 62(2), 211-230.

Charambous, C., Philippou, G., \& Kyriakides, L. (2004). Towards a unified model on teachers' concerns and efficacy beliefs related to a mathematics reform. Proceedings of the 28th Conference of the International Group for the Psychology of Mathematics Education (Vol. 2, pp. 199-206).

Christou, C., \& Philippou, G. (1998). The developmental nature of ability to solve one-step word problems. Journal for Research in Mathematics Education, 29(4), 436-442.

Clarke, D., Goos, M., \& Morony, W. (2007). Problem solving and working mathematically: An Australian perspective. ZDM, 39(5), 475-490.

Cohen, D. K. (1990). A revolution in one classroom: The case of Mrs Oublier. Educational evaluation and policy analysis, 12(3), 311-329.

Cohen, L., Manion, L, \& Morrison, K. (2011). Research Methods in Education ( $7^{\text {th }}$ edition). Oxford: Routledge,. 
Cooney, T. J. (1985). A beginning teacher's view of problem solving. Journal for Research in Mathematics Education, 16(5), 324-336.

Cope, C. (2004). Ensuring validity and reliability in phenomenographic research using the analytical framework of a structure of awareness. Qualitative Research Journal, 4(2), 5-18.

Correa, C. A., Perry, M., Sims, L. M., Miller, K. F., \& Fang, G. (2008). Connected and culturally embedded beliefs: Chinese and US teachers talk about how their students best learn mathematics. Teaching and Teacher Education, 24(1), 140-153.

Elia, I., Panaoura, A., Gagatsis, A., Gravvani, K., \& Spyrou, P. (2008). Exploring Different Aspects of the Understanding of Function: Towards a Four-Facet Model. Canadian Journal of Science, Mathematics and Technology Education, 8(1), 49-69.

Ernest, P. (1989). The knowledge, beliefs and attitudes of the mathematics teacher: A model. Journal of Education for teaching, 15(1), 13-33.

Fan, L., \& Zhu, Y. (2007). From convergence to divergence: the development of mathematical problem solving in research, curriculum, and classroom practice in Singapore. ZDM, 39(5), 491-501.

Givvin, K. B., Hiebert, J., Jacobs, J. K., Hollingsworth, H., \& Gallimore, R. (2005). Are there national patterns of teaching? Evidence from the TIMSS 1999 video study. Comparative Education Review, 49(3), 311-343.

Goos, M., Galbraith, P., \& Renshaw, P. (2000). A money problem: A source of insight into problem solving action. International Journal for Mathematics Teaching and Learning, 80, 1-21.

Grant, N. (2000). Tasks for comparative education in the new millennium. Comparative Education, 36(3), 309317.

Greer, B. (1997). Modeling reality in mathematics classrooms: The case of word problems. Learning and Instruction, 7(4), 293-307.

Handal, B. (2003). Teachers’ mathematical beliefs: A review. The Mathematics Educator, 13(2), 47-57.

Handal, B., \& Herrington, A. (2003). Mathematics teachers' beliefs and curriculum reform. Mathematics Education Research Journal, 15(1), 59-69.

Haylock, D., \& Cockburn, A. (2008). Understanding Mathematics for Young Children. London: SAGE Publications.

Hensberry, K. K. R., \& Jacobbe, T. (2012). The effects of Polya’s heuristics and diary writing on children’s problem solving. Mathematics Education Research Journal, 24(1), 59-85.

Herbert, S., \& Pierce, R. (2011). Revealing educationally critical aspects of rate, Educational studies in mathematics, Online First. DOI: 10.1007/s10649-011-9368-4.

Jennings, S., \& Dunne, R. (1996). A critical appraisal of the National Curriculum by comparison with the French experience. Teaching Mathematics and its Applications, 15(2), 49-55.

Jitendra, A. (2002). Teaching students math problem-solving through graphic representations. Teaching exceptional children, 34(4), 34-38.

Jitendra A. K, Griffin C. C., Deatline-Buchman A., Sczesniak E. (2007) Mathematical problem solving in thirdgrade classrooms. Journal of Educational Research. 100(5), 283-302.

Kaiser, G. (2002). Educational philosophies and their influence on mathematics education—An ethnographic study in English and German mathematics classrooms. ZDM, 34(6), 241-257.

Kaiser, G., Hino, K., \& Knipping, C. (2006). Proposal for a framework to analyse mathematics education in Eastern and Western traditions. Looking at England, France, Germany and Japan. In F. K. Leung, K. Graf, \& F. J. Lopez-Real (Eds.), Mathematics education in different cultural traditions-a comparative study of east asia and the west. The 13th ICMI Study, New ICMI Study Series (Vol. 9, pp. 319-351). Springer.

Kapa, E. (2001). A metacognitive support during the process of problem solving in a computerized environment. Educational Studies in Mathematics, 47(3), 317-336.

Kelly, C. A. (2006). Using manipulatives in mathematical problem solving: A performance-based analysis. Montana Mathematics Enthusiast, 3(2), 184-193.

Kilpatrick, J. (1985). A retrospective account of the past 25 years of research on teaching mathematical problem solving. In E. Silver (Ed.), Teaching and learning mathematical problem solving: Multiple research perspectives (pp. 1-15). New Jersey: Lawrence Erlbaum Associates. 
Kvale, S., \& Brinkmann, S. (2009). InterViews: Learning the craft of qualitative research interviewing. London: SAGE Publications.

Lam, T. (2006). Group problem-solving among teachers: A case study of how to improve a colleague's teaching. Social Psychology of Education, 9, 273-299.

Leikin, R. (2003). Problem-solving preferences of mathematics teachers: Focusing on symmetry. Journal of Mathematics Teacher Education, 6(4), 297-329.

Leikin, R., \& Kawass, S. (2005). Planning Teaching an Unfamiliar Mathematics Problem: The Role of Teachers' Experience in Solving the Problem and Watching Pupils Solving It. Journal of Mathematical Behavior, 24(3-4), 253-274.

Lester, F. K. (1994). Musings about mathematical problem-solving research: 1970-1994. Journal for Research in Mathematics Education, 25(6), 660-675.

Leung, F. K. (1995). The mathematics classroom in Beijing, Hong Kong and London. Educational Studies in Mathematics, 29(4), 297-325.

Marshall, S. P. (1995). Schemas in problem solving. Cambridge: Cambridge University Press.

Marton, F. (1981). Phenomenography-describing conceptions of the world around us. Instructional science, 10(2), 177-200.

Marton, F. (1994). Phenomenography. In T. Huson, \& T.N. Postlethwaite (Eds.) The international encyclopedia of education ( $2^{\text {nd }}$ ed., Vol. 8, pp. 4424-4429). Oxford: Pergamon Press.

Mason, J., Burton, L., \& Stacey, K. (1982). Thinking mathematically. London: Addison-Wesley.

Metallidou, P. (2009). Pre-service and in-service teachers’ metacognitive knowledge about problem-solving strategies. Teaching and Teacher Education, 25(1), 76-82.

NCTM. (2000). Principles and standards for school mathematics. Reston VA: NCTM.

Nesher, P., \& Hershkovitz, S. (1994). The role of schemes in two-step problems: Analysis and research findings. Educational Studies in Mathematics, 26(1), 1-23.

Nesher, P., Hershkovitz, S., \& Novotna, J. (2003). Situation model, text base and what else? Factors affecting problem solving. Educational Studies in Mathematics, 52(2), 151-176.

Nunokawa, K. (1994). Improving diagrams gradually: One approach to using diagrams in problem solving. For the Learning of Mathematics, 14(1), 34-38.

Nunokawa, K. (1995). Problem solving as modelling: a case of augmented-quotient division problem. International Journal of Mathematical Education in Science and Technology, 26(5), 721-727.

Nunokawa, K. (2005). Mathematical problem solving and learning mathematics: What we expect students to obtain. The Journal of Mathematical Behavior, 24(3-4), 325-340.

OECD. (2007). Science competencies for tomorrow's world. Organisation for Economic Co-operation and Development.

Palm, T. (2008). Impact of authenticity on sense making in word problem solving. Educational Studies in Mathematics, 67(1), 37-58.

Pólya, G. (1945). How to solve it: A new aspect of mathematics. New Jersey: Princeton University Press.

Pólya, G. (1954). Mathematics and Plausible Reasoning. New Jersey: Princeton University Press.

Pólya, G. (1981). Mathematical Discovery: On Understanding, Learning, and Teaching Problem Solving. New York: Wiley.

Rowland, T. (2003). Mathematics as Human Activity: A Different Handshakes Problem. The Mathematics Educator, 7(2), 55-70.

Santagata, R. (2004). ‘Are you joking or are you sleeping?’ Cultural beliefs and practices in Italian and US teachers’ mistake-handling strategies. Linguistics and Education, 15(1-2), 141-164.

Schein, E. H. (1992). Organizational culture and leadership. San Francisco: Jossey-Bass.

Schmidt, W. H., Jorde, D., Cogan. L. S., Barrier, E., Gonzalo, I., Moser, U., Shimizu, K., Sawada, T., Valverde, G. A., McKnight, C., Prawat, R. S., Wiley, D. E., Raizen, S. A., Britton, E. D., \& Wolfe, R. G. (1996).

Characterizing pedagogical flow: An investigation of mathematics and science teaching in six countries. Kluwer Academic Publishers. 
Schoenfeld, A. (1985). Mathematical Problem Solving. New York: Academic Press.

Schoenfeld, A. H. (1992). Learning to think mathematically: Problem solving, metacognition, and sense making in mathematics. In D. Grouws (Ed.), Handbook of research on mathematics teaching and learning (pp. 334370). New York: MacMillan.

Shahvarani, A., \& Savizi, B. (2007). Analyzing Some Iranian-High School Teachers’ Beliefs on Mathematics, Mathematics Learning and Mathematics Teaching. Journal of Environmental \& Science Education, 2(2), 54-59.

Sin, S. (2010). Considerations of Quality in Phenomenographic Research. International Journal of Qualitative Methods, 9(4), 305-319.

Smidt, S., \& Weiser, W. (1995). Semantic structures of one-step word problems involving multiplication or division. Educational Studies in Mathematics, 28(1), 55-72.

Stein, M. K. \& Kaufman, J. H. (2010). Selecting and Supporting the Use of Mathematics Curricula at Scale. American Educational Research Journal, 47(3), 663-693.

Stein, S. (2000). Equiped for the Future Content Standards. What Adults Need To Know and Be Able to Do in the $21^{\text {st }}$ Century. Washington: National Institute for Literacy.

Strauss, A. L., \& Corbin, J. M. (1998). Basics of qualitative research: Techniques and procedures for developing grounded theory. London: SAGE Publications.

Tan, O. S. (2003). Problem-based Learning Innovation: Using problems to power learning in the 21st century. Cengage Learning.

Taplin, M., \& Chan, C. (2001). Developing problem-solving practitioners. Journal of Mathematics Teacher Education, 4(4), 285-304.

Thompson, A. G. (1984). The relationship of teachers' conceptions of mathematics and mathematics teaching to instructional practice. Educational Studies in Mathematics, 15(2), 105-127.

Thompson, A. G. (1985). Teachers' conceptions of mathematics and the teaching of problem solving. In E. A. Silver (Ed.), Teaching and learning mathematical problem solving: Multiple research perspectives (pp. 281-294). Hillsdale, NJ: Lawrence Erlbaum.

Van Dooren, W., Verschaffel, L., \& Onghena, P. (2003). Pre-service Teachers’ Preferred Strategies for Solving Arithmetic and Algebra Word Problems. Journal of Mathematics Teacher Education, 6(1), 27-52.

Yin, R. K. (2009). Case study research: Design and methods. London: SAGE Publications.

\section{Appendix}

The interview protocol

\begin{tabular}{|c|c|c|}
\hline Belief dimension & Problem-solving belief & Examples of questions \\
\hline Nature of mathematics & $\begin{array}{l}\text { Nature of mathematical problems } \\
\text { and problem solving }\end{array}$ & $\begin{array}{ll}1 & \text { What is a mathematical problem to you? } \\
2 & \text { What characteristics should a good mathematical proble } \\
3 & \text { Can you give me examples of mathematical problems fr } \\
\text { experiences? }\end{array}$ \\
\hline
\end{tabular}




\begin{tabular}{|c|c|c|c|}
\hline $\begin{array}{l}\text { Mathematics teaching in } \\
\text { general }\end{array}$ & $\begin{array}{l}\text { Teaching in problem-based } \\
\text { activities. }\end{array}$ & 3 & $\begin{array}{l}\text { What should teachers be doing during problem-based ac } \\
\text { In what ways, and for what purposes, can problem-base } \\
\text { mathematics lessons? Are there different ways? } \\
\text { How can teachers organise the classroom for problem-b } \\
\text { ask the pupils to work individually, in pairs or groups? }\end{array}$ \\
\hline $\begin{array}{l}\text { Mathematics learning in } \\
\text { general }\end{array}$ & $\begin{array}{l}\text { Learning in problem-based } \\
\text { activities }\end{array}$ & 2 & $\begin{array}{l}\text { What benefits do learners gain from their interaction wi } \\
\text { any? } \\
\text { What should someone do, in your opinion, in order to in } \\
\text { solving skills? } \\
\text { What difficulties can problem-based activities create for } \\
\text { mathematics? }\end{array}$ \\
\hline $\begin{array}{l}\text { Self-efficacy about } \\
\text { mathematics }\end{array}$ & $\begin{array}{l}\text { Self-efficacy in solving } \\
\text { mathematical problems }\end{array}$ & 1 & $\begin{array}{l}\text { How would you describe yourself as a problem solver? } \\
\text { How do you feel when you face a mathematical problen } \\
\text {-What do you do when you face difficulties solving a pro } \\
\text { overcome these difficulties? }\end{array}$ \\
\hline $\begin{array}{l}\text { Self-efficacy about } \\
\text { mathematics teaching }\end{array}$ & $\begin{array}{l}\text { Self-efficacy in using problem- } \\
\text { based activities in future teaching }\end{array}$ & 2 & $\begin{array}{l}\text { How do you feel about the idea of using problem solvin } \\
\text { Suppose you were teaching a class of pupils. Would you } \\
\text { problem-based activity on a topic of your choice? What } \\
\text { doing? What would pupils be doing? } \\
\text { Suppose some children face difficulties during the probl } \\
\text { would you do in order to help them? }\end{array}$ \\
\hline
\end{tabular}

